To cite: Sedeke, K., \& Arora, P. (Forth). Top ranking fashion blogs and their role in the current fashion industry, First Monday

\title{
Title
}

Top ranking fashion blogs and their role in the current fashion industry

\author{
Authors \\ Kristina Sedeke \\ Email: k.sedeke@gmail.com \\ $\&$ \\ Payal Arora \\ Email: arora@eshcc.eur.nl
}

Web: www.payalarora.com

Department of Media and Communication,

Faculty of History, Culture and Communication

Erasmus University Rotterdam 


\section{Top Ranking Fashion Blogs and their role in the current Fashion industry}

\section{Introduction}

Social media is a digital platform with a wide impact on personal as well as business communication. A communication model where the addresser sends messages to receivers has been taken over predominantly by a new dynamic model where all participants have the opportunity to actively interact during the entire communication process. Concerning the fashion industry, there is hesitance to start communicating in this manner as the character of this media brings potential risk of losing control over their consumers. Despite this reticence, social media is recognized as being beneficial in the area of public relations and marketing of fashion as its products are essentially cultural artifacts that stem from social trends and norms and can effectively be circulated through the Web 2.0 sphere.

Within the last decade, fashion has become more of a global industry catering to transnational customers with diverse lifestyles, religions, and cultures which makes the recognition of and identification with particular customers more complex (Easey, 2002). Simultaneously, the radical change in communication allows users to participate, follow and discuss any trend and fashion news and purchase fashion items easily online. In particular, the blogosphere has become a prime arena within which fashion consumers reside online, bringing to question who and what are the influencers within these new digital and cultural spaces in the fashion industry. Blogging in general is considered a popular form of online journalism, enjoying the attention of users due to the platform's personal and interactive approach versus the standardized treatment through mainstream media. Fashion blogs are perceived as a 'street of fashion,' as a source of authenticity and a display of the actual use of fashion by the general public (Bollier and Racine, 2005). However, this new cultural sphere continues to be resisted by established fashion brands and designers who do not incorporate them into their corporate communication (Okonkwo, 2007; Guzelis, 2010). Fashion bloggers 
are looked upon skeptically as they are viewed to not have the proper expertise guaranteeing quality and credible reporting (Lichtenstein, 2009). This is not to say that fashion bloggers are

not influential; in fact, these amateur-experts have proven an impressive capacity to build up a wide audience following, and have even impacted mainstream media and the fashion industry. While we are aware of these trends, few studies have shed light on the nature and characteristic of this new cultural and online domain of the fashion industry.

Thereby, this paper focuses on some of the most effective blogs and bloggers, delving into who they are, what kinds of strategies do they employ to attract a wide audience and what are the range of characteristics that make an effective blog. The aim of this paper is to enhance the understanding of this new cultural realm, especially in three avenues: identity of bloggers, the culture of space of their blogs, and their actual and potential use as a tool of fashion marketing and brand management.

\section{Review of Literature}

\section{Social Media, Businesses and Audiences}

Kaplan and Haenlein (2010) claim that $75 \%$ of Internet surfers started using social media in 2008 by joining social networks, reading blogs, contributing reviews to shopping sites; which represents a significant rise from $56 \%$ in the previous year. Therefore it is reasonable to say that social media signals a revolutionary trend that should be of interest to companies operating in digital space. However, firms admit that they are not comfortable in an environment where consumers can freely communicate with each other; within this platform, businesses have increasingly less control over information concerning their activities and reputation. Nowadays, if an Internet user types the name of any leading brand or corporation into Google search, what comes up among the top five results usually include not only 
corporate websites but also amateur sites. Faulds and Mangold (2009) agree that the opportunity of communication between hundreds or even thousands of people about the products or services without any control of the company itself can be daunting, and that the impact of consumer-to-consumer communication has been greatly magnified in the marketplace. However they argue that social media should rather be seen as a hybrid element of the promotion mix, because it enables companies to talk to their customers (traditional sense of the promotion mix) as well as it enables customers to talk directly to each other (nontraditional sense of the promotion mix); “even though the content, timing, and frequency of social media conversations are outside of the managers' control, they must learn how to shape consumers discussions in a manner that is consistent with the organization's mission and performance goals" claims Faulds and Mangold (2009, p. 357). They further add that blogs and other promotional tools should be seen as an opportunity and challenge rather than a threat as they are the key to contemporary markets, and the fashion industry is no exception.

\section{The Contemporary Fashion Industry}

Fashion is not something that exists in dresses only. Fashion is in the sky, in the street, fashion has to do with ideas, the way we live, what is happening - Coco Chanel

Fashion is an ongoing changing process which in regular cycles brings new trends into practically any human activity; from medicine to music (Easey, 2002, p. 10). It is a product of the time and must be viewed within a broader cultural context such as the designers' ethnic and social background, social mores and attitudes, technological innovations, and the economic and political conditions (English, 2009, p. 6). For fashion to serve as a continual change, two criteria are essential - creative design skills and identification with customer preferences. While design skills are a matter of talent, identification with customers is a matter of marketing which can provide additional knowledge and skills needed to ensure that 
the creative component is used to the best advantage, allowing business to succeed and grow. Easey (2002) argues that because of the nature of the fashion industry where change is crucial, practices of fashion marketing are slightly different from other marketing areas. Fionda and Moore (2008) further develop Easey's theory and claim that marketing and branding fashion goods is more complex than in other sectors because of the velocity and vastness of this industry; brands and designers must twice a year produce brand new collections, containing a variety of items (many brands do not focus just on clothing but also on accessories and shoes, and often do not only produce female lines but also male and children) which are often distributed worldwide.

Beside the factors mentioned above, another essential component in fashion marketing is a strong brand image. As Lee et al. (2009) argue on why people talk about particular brands in a certain way and why they buy (or do not buy) its products is to some extent a matter of brand image. Image is more than a name, logo, slogan and design. It is the whole concept containing symbolic meaning, induced associations, ideas and attitudes of the brand. For instance, "a jeans brand Levi’s is not just an eye-catching red label; it has developed core urban-hip user imagery in youngsters' minds" claim Lee et al. (2009, p. 64).). Further, they argue that the fashion market strongly depends on creating and maintaining a distinctive, desirable and constant image, bringing additional value and brand differentiation. Hitt, Ireland and Hoskisson (2009) state that the main task for fashion marketing is to achieve competitive advantage by differentiation of the brand from direct competitors. Differentiation in general can be based on products, services, channels or people but in fashion "it is most likely based on the overall brand image, comprising general qualities of the brand and determining its initial position at the market" (p. 133).

Another reason why brands and designers need to build a strong image is the lack of copyright protection. As Blankley (2010) states, there is no intellectual property protection in 
the fashion industry, which means that anybody can copy any design from anybody and present it as his own. The result of this lack of legislative coverage together with an ongoing pressure to release new collections is the collaborative character of the fashion industry. Haute couture designers commonly search for inspiration in other culture fields, especially the music and film industry, street fashion or vintage collections. According to Blankley (2010) this mechanism determines the emergence of new global trends, and leads to the democratization of fashion. However she further notes that as designers cannot rely on legislative support, they solve this issue by copying themselves and directly cooperating with mainstream brands (as for instance custom collections of Versace for H\&M), or by creating a strong image for particular brands where the copy would be perceived as an obvious fake (as for instance red sole typical for Christian Louboutin or checkered pattern typical for Burberry).

Based on the key principles of contemporary fashion, fashion marketing can be clarified as a management process concerned with anticipating, identifying and satisfying actual customer needs in order to meet the long-term goals of the organization, and continuously building or maintaining a strong corporate image characterizing the brand in the market. In order to reach those goals, fashion marketing uses common techniques of advertising and market research with the addition of tools specialized for the fashion industry such as product development, branding, pricing and forecasting (Easey, 2002). Moreover, social media is seen as a new platform to be included in this list as their features have the potential to assist in such tasks. However the following section shows that despite the potentially beneficial feature of social media, these technologies are used sporadically within the fashion industry. 
Despite the wide potential of social media, the fashion industry is resistant when it comes to its use. In fact, in the fashion industry Internet technologies are used as a distribution channel rather than as a communication device. Hines and Bruce (2007) state that fashion retailers use the Web primarily to display the most up-to-date collections and sell them online directly to their customers, and that despite the continued speculation about the limited abilities and disadvantages of online distribution (some designers and brands do not enable international online purchases because of the high cost in case of reclamation and eventual complication with intercontinental transport), the volume of clothes, accessories and foot wear sold via the Internet has grown steadily - from 25 to 30 per cent a year since 2000. As online purchasing has become a profitable distribution channel, the central attention of fashion marketers and PR executives is paid to corporate websites where online shopping is concentrated. Within the fashion industry, social media devices are used sporadically; mostly as an additional tool, promoting official websites and supporting public knowledge of the brand. Hines and Bruce (2007) criticize this practice and note that fashion marketers should be aware of the contemporary public demand of interactive communication caused by the emergence of social media platforms such as blogs, and the need for elaborate customer segmentation and identification determined by the global character of the industry.

"We gotta do larger sizes," a tweet from Robert Duffy (CEO of Marc Jacobs, a creative director of Louis Vuitton) reached more than 26,000 followers and caused the reaction of Jacobs himself re-tweeting "I'm with you, as soon as I'm back to NY I'm on that." This created an excitement of transparency and customer involvement in the business mechanics of the fashion industry, promising a new kind of relationship between designers and/or brands, and their customers (Boure, 2010). Guzelis (2010) agrees, stating that in the current environment it is extremely important for brands "to know and be able to influence the 
'what' and 'how' people talk about the product or brand, and what influences their buying decisions" (p.16). For such purposes, social media can play a mediator role between the fashion industry and its consumers. Reviewing the nature of the current fashion industry and used practices in fashion marketing, brand management and public relations, it is obvious that Marc Jacobs should be perceived as an exception than a rule. Despite the fact that the emergence of new media technologies has changed the conditions under which the fashion industry operates, it seems like the industry itself has difficulties to adjust to this new environment and concerns continue on controlling the expertise domain on shaping opinion and taste in fashion. Interestingly, despite this resistance, fashion blogs have taken on a prominent role in this industry, challenging its conventional business culture.

\section{The culture of Blogs and their Spheres of influence}

Statistics about the blogosphere are spectacular. In 2006, Technorati (an Internet search engine for blogs) posted 49.8 million blogs with more than 2 billion links - approximately 75 thousand new blogs and 1.2 million posts were created every day, and as the Institute of Policy Development claims, blogs are projected to double in number every six months (Guzelis, 2010, p. 19). According to statistics published by Royal Pindgom (2011), the total amount of blogs on the Internet recently reached 152 million.

There are various theories concerning motives for blogging as well as for following blogs. For instance Nardi et. al. (2004) propose five general motives why people blog documenting one's life, expressing deeply felt emotions, forming community forums, providing commentary and opinions, and articulating ideas through writing, whereas Boram, Sookyoung and HaeJung (2010) see personal needs, particularly self-reflection, selfactualization, and/or self-satisfaction as an initial motive which makes people blog. On the other hand scholars such as Shao (2009) and Leung (2009) see engagement as a key feature of 
blogs giving an explanation for its recently acquired popularity, and state that people consume UCC (Users Created Content) for the same reasons why they watch television; they use it to fulfill their recognition, entertainment, and cognition needs, "the respondents believed that through the content-generation online process, they would have the opportunity to be recognized, gain respect, publicize their expertise, learn more of the world, socialize with friends and be entertained" (Leung, 2009, p. 1337).

Another feature which is specific for blogs and for UCC's in general, and which is highly appreciated by users is the time efficiency, easy-use, and multidirectional communication. Modern users are facing a decrease in their free time and thus appreciate the character of blogs based on simplicity and efficiency, as well as the many-to-many nature of communication specific for this media, bringing high levels of interactivity and space for discussion and sharing opinions (McMillan, 2006; Kuhn, 2007; Shao, 2009; Arora, 2012). Because of this, the nature of communication blogs can be considered as a new electronic form of word-of-mouth (e-WOM), enabling a wide spread of valuable information among the blogosphere, or even as a new form of agenda setting; "the network structure enables that any interesting information, case or argument can appear on the top of blogosphere, and if a critical number of elite blogs raise a particular story, it can catch the attention of mainstream media outlets and even transmit public opinions" (Farrel and Drezner, 2007, p. 24). Lichtenstein (2009) argues that blogs are a new form of online journalism representing an important source of information and knowledge for members of the public. However, Blood (2003) claims that blogs cannot serve as an information source equal to journalism because of the lack of original reporting which she considers as the heart of journalism, and adds that even a blog written by a journalist does not necessarily qualify as journalism, as it is the practice that defines the practitioner, not the other way around (p. 61). Lichtenstein (2009) objects that there is a disorder in valuating information; certain scholars and professionals see 
blogs and other forms of online published knowledge as undermining the truth and belittling expertise, experience and talent, while bloggers appreciate quite different aspects of knowledge. They referred to the value of having witnessed events in person, the value of having local knowledge, and of being a trustworthy person. Some bloggers even hold a strong negative opinion of experts as elitists who cannot be trusted in their opinions and who serve to control information and knowledge flow. Which does not mean that bloggers doubt expert knowledge; "they rather mistrust experts as people, assign them traits such as elitism and the inability of independent unbiased thinking" (p. 1041).

Zhao and Kumar (2012) classify the blogosphere as a "world-wide community of blogs" (p. 3) that is becoming more popular and assuming greater importance in the business world. According to the Alexa ranking of Web traffic, popular blogging services Blogger.com and Worldpress.com rank $21^{\text {st }}$ among all sites on the Web which raise their business value, and accordingly shape their publishing behavior and topic coverage. Sun and Zhu (2011) add, "many scholars argue that content providers, when incentivized by ad revenue, are more likely to tailor their content to attract 'eyeballs,' and as a result, popular content may be excessively supplied" (p. 1). In order to justify this statement they launched an ad-revenue-sharing program initiated by a major Chinese portal. Participating blogs allowed the site to run ads on their blogs and received $50 \%$ of the revenue generated by these ads. After analyzing 4.4 million blog posts, Sun and Zhu (2011) discovered that (compared to posts of blogs not participating in this program) selection of current popular topics - stock market, salacious content and celebrities - increased by about $13 \%$ after this program took effect. They further claim that the quality of posts increased as well.

In order to gain a comparative outlook on the contemporary blogosphere, we need to look at data emerging from analysis' of blogs focused on different industries. For instance, Pan, MacLaurin and Crotts (2006) during their analysis of travel blogs found that travel blogs 
abound with a high level of personalization in terms of detailed descriptions of the bloggers profile and a loose writing style. During their study they primarily focused on blog posts covering Charlestone, South Virginia, as a travel destination, and discovered frequent use of certain key words among all the blogs. Regarding use of blogs in marketing, they argue that blogs are being underutilized by the commercial sector as they found that despite the presence of rich and valuable feedback concerning all aspects of Charlestone as a travel destination, there was no single interaction from any professional operating in tourism in this location. Results of Discher's (2007) study on car blogs confirm this finding, where it was found that the most valuable car blogs are not managed by any professional from this industry. Further, Berent and Navigli (2006) observed specific jargon created and commonly used by bloggers and their followers.

Despite the unquestionable fact that blogs are a huge phenomenon with tremendous versatile potential, it is important to note that most blogs are abandoned soon after their creation (from 60 to 80 per cent of blogs within the first month), and that most blogs are rarely referred to by others, since they are read only by a small social circle of the authors and thus stay practically without an audience (Caslon, 2009). Lastly, it is important to mention that blogs concern specific group of users rather than the mainstream audience. Writing as well as reading blogs is done by the young generation - $90 \%$ of bloggers are in their 20's and $79 \%$ of blog readers are younger than 40 . In fact, as the results of a survey conducted by DBB London concerning the knowledge of new technologies among the middle class society of the United Kingdom showed, $70 \%$ of this demographic was not sure what a blog means (Caslon, 2009). Hence, in such circumstances, when a blogger does attract a large audience, it is indeed worthy of investigation.

\section{Fashion Blogs}


Being 'fashionable' requires certain features - keeping up with the latest collections of right brands and designers, going to the right places, and communicating with the right people. In fact fashion is greatly privileged and it's accessing costs are high. However the emergence of UCC allows participation in this specific subculture with no material limitations and makes fashion more accessible and democratized. Although electronic-based fashion is without barriers and practically anybody can express and spread her fashion ideas, it does not mean that there are no costs at all, "studies on the active blogging movement illustrate how rapidly a fashion cycle transpires online. Ideas circulated on blogs are generated, discussed, embellished, and forgotten on a quotidian cycle" explain Liu and Donath (2006, p.2). They further claim that major costs in displaying high-quality electronic-based fashion lie in accessing the freshest and most salient information. Since the distribution of information online is low-cost, more time and effort must be invested in finding high quality information. As a result of this requirement, fashionable bloggers spend enormous amounts of time each day reading other blogs, seeking obscure websites, and writing posts in an attempt to be ahead of the fashion cycle. Hauge (2006) claims that the blogs share on coverage of fashion news is rapidly increasing with several advantages over classic media - blogs can quickly react and respond to current happenings which fit well to fashion news. Additionally, it can create an interactive environment that serves as good marketing; for instance in Sweden, one of the most profiled journalists and writers mentioned in her blog how much she liked a certain brand and why, and the brand appreciated that and sent her one of their garments. She reported that on the blog and started a buzz on this particular brand. This served as effective and novel marketing in this cultural sphere (Hauge, 2006). In 2009, Burberry launched their first campaign through fashion blogs, gaining enormous success and reaching about two million page visits every day (Leitch, November $14^{\text {th }} 2009$ ). However it is important to note that Burberry as well as previously mentioned Marc Jacobs is exceptional in the fashion 
industry, while the majority of well-known designers or brands such as Christian Dior,

Channel or Versace still do not use blogs in any way. Overall, a lot of research has been done in the area of general blogging - its motives, business opportunities, comparison with classic journalism, impact on followers, but little research has been done in the area of the contemporary fashion blogosphere; in a sense, of properly identifying what constitutes as the most effective blogs and providing an explanation on what determines them to appear on the top of the fashion blogosphere.

\section{Methodology}

Blogs appearing in the top ranking list of the fashion blogosphere was determined as a main focus of this paper, expressed by the following research question: What determines an effective blog in the contemporary fashion blogosphere? To address this topic, the term "an effective blog" must be explained in greater detail. McDonald and Ounis (2008) claim that an "effective blog" is a blog which appears on the top of search engines and thus allows to be discovered by random users searching for information of mutual interest. Yang and Lim (2009) argues however that we should not just focus on the technological outcome through online searches, but also on the salience of the narrative structure, dialogical self, blogger credibility, and interactivity. For the purpose of this paper an effective blog is simply a blog ranked in the top fashion index and with a significant following by engaging a vast audience. Another aspect to explore here is the identity of authors of these blogs, and the nature and culture of blog space created. In order to examine the first aspect, the professional and educational background, gender, age, place of residence, affiliation and purposes of blogging by these top bloggers are documented. For examining the culture and content of these blogs, we examine the chosen topics, writing style, graphic layout, division into rubrics, character of accompanied photos and videos as well as the nature and level of interaction and engagement 
with the audience through comments, discussions, content sharing, and presence of these blogs within social networking sites. In doing so, we contribute to the last sub-question; to what extent do blogs serve as a tool of fashion marketing and brand management? To answer this question the actual or potential presence of promotional strategies of certain brands or designers which can be considered as an external marketing tool was examined.

Qualitative content analysis was chosen as an optimal method to analyze written, verbal and visual communication messages; we classified them into related categories, sharing common meanings and patterns (Cavanagh, 1997). We took on an inductive approach given the explorative nature of this topic. The limitations of this technique might be the subjective data interpretation of the researcher influenced by her own perspective, and eventual excessive simplification of data. Both possible confines were taken into account during the data collection and data interpretation to achieve the most valid and reliable results. For sampling the ranking list "The 10 best...Fashion bloggers" assembled by Alice Fisher, a style editor of The Observer, and published by The Observer and by the Guardian.co.uk on Sunday $21^{\text {st }}$ February 2010 was chosen as the most suitable chart for this research. Even though the criteria of selecting blogs for this ranking were not found, the fact that this chart was published within the settled rubric (The 10 best...) of respectable and credible publication agencies made this a suitable choice. Another ranking which was considered as the source of sampling for this research was the "Top 50 fashion blogs" assembled by Blog rank. Although the criteria of this ranking were, unlike the Fisher's ranking, known and clearly explained, the chart was not used because of the inclusion of blogs such as Style.com which operates as an online magazine, employing its contributors, and making profit through advertisements. Thus Fisher's ranking was chosen for the reliability of its origin, optimal amount of included blogs, and its inclusive nature, suiting to the aim of this research (The complete list of blogs included in this ranking is attached in the Appendix A1). 


\section{Results and Discussion}

The inductive content analysis showed that blogs included in Fisher's ranking contains a wide range of blogs, covering diverse topics. The aim of this research is to find general underlying patterns common to the 'top' fashion blogs concerning the authors, culture of space, and potential use in fashion public relations, marketing and brand management. This section explicitly demonstrates shared patterns and features, regarding not only areas covered by SubQuestion 1, 2 and 3, but certain additional discoveries. Key findings are illustrated through extracts from blogs which is believed to reflect particular features in the most suitable way.

\section{Identity of Bloggers and Culture of blog space}

The first part of the research focused on addressing Sub-Question 1: Who are the bloggers within the top ranks in the fashion blogosphere? In order to answer this question professional and educational backgrounds and identities of these bloggers were analyzed. It was found that fashion bloggers do not represent any specific social group; on the contrary, results showed that the chosen ranking consists of a variety of bloggers; high-school students, emerging journalists and writers as well as formal photographers, film makers, within a wide age range of 17 to 53. Most authors' place of residence was the United States or Europe. Based on this finding, we can claim that these top bloggers come from outside the professional fashion industry, and do not work for any designer or brand in any position, as well as the fact that the West continues to dominate in the fashion blogosphere. Secondly, addressing Sub-Question 2 on the nature and culture of these blogs that contribute to their top ranking in the fashion blogosphere, we focused on the page layout, selection of topics, writing style, and level of interaction and engagement with the audience. In doing so, we found the following features in common: 
a) Simplicity and Personalization

Concerning the page layout, selection of topics and writing style of posts, a common pattern visible was the simple clear layout and highly personalized content. The analysis showed that bloggers keep their blogs simple; use clear black and white layout, simple fonts, and division into sections according to the date of publishing of posts. Selection of topics purely belongs to blogger's personal preferences and interests as well as the nature of the post which usually mirrors blogger's personal convictions and opinions. The topics for posts are often generated from the blogger's every-day life as they regularly pertain to events in which the bloggers recently participated, people whom they met, and things which they did. However fashion and style still dominates the posts, presented in an informal way, using humor, colorful expressions, metaphors and idioms. A diary style is used, underlined by the "I" form in which all posts are written, and by the nature of accompanied photos and videos, usually made by the blogger herself, or provided by other bloggers with blogs concerning similar topics, but seldom from official media or a public relations source. For instance, Style Rookie published on May $3^{\text {rd }} 2012$ the following:

Claire and two friends both named Alex and me performed at V-Day, a good, loud celebration of vaginas. Autumn took those photos. The last one is me in the last hour of my 16th birthday a couple weekends ago. I am wearing my friend's sweater, a skirt I got to keep from the Wren shoot, and a jacket gifted to me by Risto.

The personalization of the content is further multiplied by sections "About me" which seem to be narrated in a story form of their life, with background information, motives for blogging, and reasons for choosing a particular blog orientation.

b) Background Information and Unusual Approaches 
Beside the personalized approach, these blogs showed that the selection of posts and their content covers different kinds of information and approaches than classic mainstream media. Given that bloggers included in Fisher's ranking do not come from the professional world of fashion, their content is not outcome-driven nor are they hyperlinked to brands. Admittedly, some bloggers who arguably are on the margins of this profession do cooperate with fashion brands and designers (such as photographer Scott Schuman or set designer Gary Card). For instance; set designer Gary Card on his blog Gary.card.iology regularly informs about his newest sets and installations, including information about what kinds of instruction he gets from his clients, what he finds challenging and what inspires him, as is illustrated in the excerpt from one of his chosen posts from March $31^{\text {st }} 2012$ :

...I had absolutely no idea what I was coming in to paint was so exciting, the risk involved really interested me. The only thing I had to go on was black, white and red, the rest was totally improvised...

Some bloggers started to cooperate with fashion brands due to the increasing popularity of their blogs (such as Tavi Gevinson, author of Style Rookie, or Gabriel Gregg, author of Young Fat and Fabulous). Interestingly, this creates a circular process where due to their new found status, they gain insider 'professional' knowledge via fashion businesses and brands. Here, fashion businesses, in collaborating with these amateur-expert bloggers, hope to encourage these bloggers to refer to their brands in the blog posts. However, much of what these bloggers usually focus on is the creative process of fashion, and the actual use of fashion in every-day life, making the casual insertion of brands within their post a challenge. To give a concrete example, majority of posts by Tavi Gevinson are visual illustrations of the origins of actual trends. For instance, in a chosen post named 'Technicolor' published on February $1^{\text {st }}$ 2012, she informs about the inspiration of trends for the upcoming season from the retro style 
of 60`s and 70`s. In this narrative there was little room for brand plug-ins. However, Tavi Gevinson did manage to insert the brand Rodarte in one of her blog posts; In Rodarte's media coverage they claimed old Disney movies as the main inspiration for their actual fashion season. Tavi Gevinson used this information and searched for clear evidence to prove these statements, acting as a watchdog for authenticity in the fashion world.

Overall, these top bloggers in general center their attention on every-day use of fashion (by themselves or by random people), on combinations of different styles and fabrics, on emerging designers, vintage boutiques, and other aspects that fall outside of main stream media attention. Some bloggers are particularly known for following a niche and non-main stream area such as the blog Young Fat and Fabulous, nowadays known as Gabi Fresh launched by Gabriel Gregg. Gregg started blogging when she graduated from college (in Chicago with a degree in journalism) and could not find a job as a fashion journalist. Her first blog Young Fat and Fabulous documented her personal life as a plus size girl with a passion for fashion. Gabi was posting pictures of herself, ignoring all 'rules and tips' concerning fashion for plus sizes women, demonstrating that extra weight is not an obstacle to follow fashion trends. In the section "About" she literally says, "if you love fashion but you're sick of being told to wear A-line skirts, wrap dresses, boot cut jeans, and slimming prints, this is the blog for you. “

To conclude, the content of analyzed blogs disposes different kinds of information from that of mainstream media. These bloggers invest tremendous effort to give authenticity through the tracing of certain fashion trends historically, verifying certain fashion industry claims, showing the behind-the-scenes of the fashion world through their peripheral and outsider-insider status, and at times contradict popular isms of dos/don'ts in fashion. Thus these blogs carve a niche for themselves by serving as a trusted and alternative source of information, filling the gap in contemporary fashion journalism. 
c) Shift in the Nature of Posts

In general these blogs follow a standard format of straight-up photos taken by the blogger herself or sometimes provided by another blogger, scans of fashion shoots and vintage magazines, accompanied by personal opinion and comments. Part of the analysis here was to detect if there was a shift in the nature of these blogs over time as they gained prominence over the years. We chose a random sampling of blog posts from each year of the lifetime of the select blogs and compared them in terms of style and substance. The comparison of currently published posts (in 2012) and posts published in previous years showed that there is no radical shift or change in the subject of post, writing style or layout. Even posts of Gabriel Gregg or Tavi Gevinson, who were complete amateurs and now are seen as respected figures in the fashion industry (for instance, at the age of 13, Gevinson was invited as a special guest to the New York Fashion Week and has appeared on the cover of Pop magazine, and was interviewed by New York Times, BBC, CBS, Teen Vogue, French Vogue), did not radically change. Arguably, this observation highlights the importance of the 'raw' and 'amateur' perspective in fostering authenticity in blogs that give it currency and staying status. While the writing style and nature of selected topics has not shifted, greater change is visible in the ratio of text and photos shared, as well as the quality, size and amount of accompanied photos. While at the start, bloggers were more text-oriented with photos as a side accompaniment, over the years, visual representation has taken on more of a center stage and become a statement in itself. Nowadays, it is common to see entire blog posts where photos are the only content of the post with a few lines to extend its meaning. Hence, from a peripheral to a core status, visualization of opinion and comment has become the mainstay of fashion posts amongst these top blogs. While this does shed light on the shift in style preference of these bloggers, one needs to keep in mind that blog audiences have also changed over these years 
where their taste, expectation and experience of blog consumption has influenced the nature of contemporary blogs.

Interestingly, while these blogs overall have stayed relatively stable over time, two blogs did undergo significant transformation - the 'High Snobiety' and 'Go Fug Yourself' blogs. These two are currently authored by a cooperative of bloggers instead of a single person, creating a variety of posts divided into sections corresponding to the interests of the different associated bloggers. While these blogs expanded and reached a professional level of management, they lost one feature which seems to be essential for these top blogs - an interactive audience. As it will be demonstrated in the following section, these top ranking blogs generally have a dynamic commenting section, operating as discussion forums. Nevertheless, a feature of multi-directional discussion was not noticeable within High Snobiety and Go Fug Yourself, where commenting sections were almost empty (maximum number of comments of analyzed posts was three). On the other hand, while their commenting section has shrunk, their presence in other platforms have expanded over these years: High Snobiety has more than 50,000 Twitter followers and more than 80,000 likes on Facebook; Go Fug Yourself has more than 63,000 Twitter followers and almost 30,000 Facebook likes. While other platforms were not looked at in detail for the scope of this paper, it is worth keeping in mind that trade-offs in one direction (loss of interactivity) due to an expanded and collaborative endeavor can expand opportunities through strategic blogger affiliation and cooperation through joining of their social capital (marked by expanding presence on different social media platforms).

d) Interactivity and Social Media Presence

This last part of the analysis of the culture of space of blogs in Fisher's ranking explores the nature of interactivity and social media presence of these blogs by looking at their comment 
section and social media accounts. As the comment section of these blogs are very active with a typical response of more than 100 comments per post, we focused on the first ten comments of posts published in February, March and April 2012. While this is a sparse sampling, it intends to give a glimpse of the nature of interactivity and encourage further analysis in particular directions in future research.

In general the nature of analyzed comments was positive, giving complimentary feedback, showing excitement and interest in the topic of the post, and sometimes also sharing their own opinion on particular subjects. The comment section usually is without any moderation or management by the blogger; to be able to leave a comment, users do not have to register, and their comments are immediately posted without any screening for negative content. Hence, trust appears to go both ways in this specific new media space. Bloggers react mainly to comments which contain questions directly addressed to them; otherwise, these discussions are often between commenters rather than between the blogger and the audience. Readers/followers of the particular blog share their opinions, react to each-others comments, and often even include links to their own blogs, concerning similar or related issues. For example, 'The Sartorialist' blog is worth looking at as it gained the highest number of comments from all analyzed blogs (usually 120 and more), and is the only blog which does not contain any text in the posts. The Sartorialist is led by the fashion photographer Scott Schuman, focusing on street fashion around the world. An interesting feature of this blog is the limited and sometimes complete lack of any broader comment which would give more information about posted photos. Instead the only texts that accompany Schuman's posts are the titles of the series of pictures which allude to where they were taken, for instance; On the street... Grand Street, New York” or On the street...Le Marais, Paris. The text on the blog comes primarily from the comments section where on average 100 users (per post) share their opinions about a particular picture and the styling of the person in that picture. In the section 
'Biography' Schuman claims that he began 'The Sartorialist' with the idea of creating a twoway dialogue about the world of fashion and its relationship to daily life. His blog has expanded to social networking sites such as Twitter and Facebook, where it reached almost 100.000 followers and 65,000 likes.

Such an extensive amount of Twitter followers and Facebook likes is not an exception among these top ranking blogs. For instance, Style Rookie has more than 60,000 Twitter followers, Style Bubble has almost 60,000 Twitter followers and more than 20,000 Facebook likes. Bloggers themselves are generally very active through other social media platforms. Particularly on Twitter, they tweet several times a day and follow hundreds of Twitter accounts. Given the sheer volume of tweets, this study focus is limited to the first twenty Twitter followers, first twenty Twitter following, and first twenty Facebook likes of all select blogs. It was found that these bloggers are followed and liked by other fashion bloggers (but not exclusively). Analysis also showed the dominance of Twitter where all analyzed bloggers have accounts and where they all actively communicate, often with each other. Eight out of ten bloggers did have a Facebook profile but this platform was not as interactive as that of their Twitter and blog space. Facebook posts were often just extensions of blog posts and the frequency of new posts on their Facebook profiles is on average several time a week versus on Twitter where it is several times a day. Some bloggers also used other social media beside Twitter and Facebook, namely Tumblr, Flickr and Google Plus. However none of those social networking sites acquired much attention from the audience.

Another noticeable feature is the Twitter account of Marc Jacobs, a creative director of Louis Vuitton and his own lines Marc by Marc Jacobs, which is followed by most of analyzed bloggers (seven out of ten). Furthermore he was the only well-known designer and fashion icon to be followed by these bloggers. This fact led to a more detailed analysis of his Twitter account and his social media presence to find an explanation of his special positioning 
as apart from other professionals in this industry. Analysis showed that unlike other designers who use PR experts, Marc Jacobs communicates on Twitter himself, and his messages are not just about fashion but also concern his personal interests and every-day life. His personalized approach and interactive nature is generally appreciated and represents a new way of corporate communication in the fashion industry.

To conclude, these findings emphasize the point that in the top ranking fashion blogs, there are no professionals from the fashion world that factors into this group. Instead, we see a diverse range of bloggers from all backgrounds, ages and educational levels participating in this forum, signaling the democratization of information within this sector. However, one cannot claim it to be globalizing as they continue to reside in the United States and Europe. Further, the spatial cultures of these blogs that attract and sustain an audience have certain common patterns of simplicity in layout, and highly personalized content based on bloggers own (subjective) opinions and experience. Interestingly, contrary to what one may expect, the nature of these blogs continues to remain stable in spite of their growth in audiences and even linkages with the fashion industry. There is much effort made in staying 'authentic' to the audiences by not commercializing their spaces or advocating for particular brands even with their strong affiliations and endorsements by the fashion sector. Instead, they indirectly capitalize on these linkages by gaining an insider perspective which makes their blog more attractive to their audiences while yet remaining on the outside. Fascinatingly, one aspect that did change was the presentation of content from more textual to more visual in nature, partly attributed to the changing taste of audiences and intent of blogs as this social media platform has matured over these years, gaining a particular culture of expectation. It is evident here that for the most part, these platforms are still not being capitalized by the fashion professionals and that Marc Jacobs serves as an exception to the rule. Further, there is much dynamism within these spaces as audiences interact with one another through positive feedback and 
sharing of experiences, resembling more a communal and intimate space of comfort than a critical arena of discussion. These 'communities' while not exclusively concentrating around blogs as they pervade across different social media platforms such as Twitter and Facebook, continue to be unique within this platform as evidenced through their high interactive, social and communal culture.

e) Presence of marketing and branding

Another aspect of this research was to explore the potential usage of these blogs as fashion marketing and brand management tools, as stated in Sub-Question 3: To what extent do blogs serve as a tool of fashion marketing and brand management? In order to explore this, we focused on the presence of features which can be considered as a tool of public relations, marketing and brand management; for instance, mentioning particular brands and designers, promoting fashion events and news from the fashion industry. In other words, to what extent are these spaces commercializing as they achieve influence in this sector? The analysis of the topics of posts, the framing of chosen subjects, and the character of accompanied photos showed that these fashion blogs do not use any official sources and base their posts exclusively on their own experience. Consequently, even major events such as Fashion Week do not appear in posts of these bloggers unless the blogger attended the event. Concretely, New York Fashion Week Fall and Winter 2012/2013 was covered only by two blogs- Style Rookie and The Sartorialist as their authors, Tavi Gevinson and Scott Schuman did participate in this event.

Even though Tavi Gevinson posted on New York Fashion Week, its central focus was on the people attending this event, and their personal styling rather than on designers and their collections presented on the runway. This underlines the claim mentioned in the previous section, that analyzed bloggers are primary interested in every-day styling and individual use 
of fashion to keep the authenticity and rootedness of their blog space. As these bloggers focused on 'what' people were wearing rather than on 'who' they were wearing, their posts hardly contained any reference to brands or marketing ploys. Although this fact was found as a common pattern for most of the analyzed blogs, there were a few bloggers whose posts did contain information that could be considered a form of publicity. One of these blogs was The Style Bubble led by Sussana Lau, focusing on British emerging designers, talented school absolvents, small boutiques outside the London center, and alternative Fashion Weeks. In her posts she very specifically explains why she likes particular designers or boutiques, what kind of clothes he makes/they have, and where people can buy them as is illustrated in this chosen post from March 2012:

Confession: I'm obsessed with neon. It was huge last year, and thankfully the trend isn't going away anytime soon. Today I met up with friend and fellow blogger Christina of Profresh Style, and we coincidentally both ended up wearing neon and black! My tulip dress is again from Very.com; the dress in my last post was by Love Label and this one is by the brand South. Since it was a bit cooler today, I paired it with one of my classic black trench coats.

Another example is the Young Fat blog, focusing on fashionable styling for plus size women and which brands were best at catering to these needs. The main aim of mentioning this blog was to point out to the open mentioning of fashion brands not present in other top ranking blogs. Besides openly mentioning brands in the posts, this blog also contains a list of favorite brands and shops permanently placed on the right panel of the central blog page, and in the comment section provides tips regarding online shopping for brands mentioned in the posts. For instance, how to determine the correct size with foreign brands, what kind of payment options are available at a particular foreign brand, or how does it work with reclamations are some tips regarding online shopping.

To conclude, there is little presence of direct marketing or branding within these ranked blogs. It seems that intrinsic to this fashion blogging culture is the need to avoid the 
mention of brands and corporations or linkages with their purchasing. However, there were some blog exceptions that did foster and educate their audiences on specific brands and shopping tips and linkages to specific fashion sites. While this does create publicity for those brands and designers, the question remains if this can be viewed as a commercialization of this platform unless it is to be found that these bloggers were paid by these designers to advertise on their behalf. However, by these facts alone we cannot conclude that this leads to a commercial and inauthentic space as one can argue that online shopping and tips is part of the communal character and trust built on this platform over these years.

\section{Discussion and Concluding remarks}

The previous section demonstrated a variety of findings on the identity of bloggers and the culture of space of the top ranking fashion blogs within the Fisher's ranking index of 2010. The non-professional and Western participants as bloggers, the simplicity, personalization, authenticity, valuation of first time experience, unusual coverage and approach to fashion, dominance of visual content, interactive multidirectional communication amongst the audiences, rich social media presence, preference of Twitter, and an almost absence of brands and designers were found as key findings across these blogs. In the following section, we situate these findings within a wider perspective.

\section{Identity of Fashion Bloggers, Culture of their Blogs, Interactivity and Marketing potential}

Scholars have found that the emergence and widespread consumption of blogs is due to the demand for a more interpersonal and casual means of communicating and processing information by the current generation geared in the nature of entertainment-education; hence the emphasis on clear and non-jargon styles in communicating and platforms of easy-use and efficiency. This explains the choice of clear layouts, humble fonts, and simple division into 
sections by the date of publishing. Despite the fact that three bloggers (out of ten) were older than 40, findings underline the larger scholarly claim that blogging is a phenomenon of the predominantly younger generation. Another feature that corresponds to current literature on blogging is the valuation of information and knowledge based on first-time experience and trust, privileging authenticity over expertise and institutional linkages. As argued by Lichtenstein (2009), bloggers and their followers appreciate personally acquired or witnessed information more than information coming from an official source.

Moreover, fashion blogs offer different approaches than mainstream media. For instance the coverage of the New York Fashion Week 2012 was done by focusing on the audience attending this event and what they were wearing versus which designers and brands were making headlines, emphasizing blog space as that which fulfills gaps that are not addressed by mainstream media. The findings indicate that the growth and development of blogs towards mainstream media seems to come with depersonalization and loss of an interactive audience, arguably a prime currency of this space. This may partly explain why the appearance and nature of these ranked blogs have for the most part not changed radically or become more 'commercialized' since their beginning in spite of their current acquired privileged position in the fashion blogosphere. This serves as a significant dilemma for businesses in the fashion industry on how to capitalize on these new media spaces, given that the very culture of these blogs are antithetical to overt commercial interests and marketing agendas of fashion businesses. For future research, it is worth comparing different top ranking blogs from different sectors (such as politics, music, museums, healthcare) to examine to what extent are amateur blog spaces capitalized upon for commercial interest and if so, what are the explicit and implicit strategies employed. What is also important to keep in mind is that while the very fact that these top ranking blogs do not have a single fashion professional/company in their midst signaling its democratic nature, one cannot say the same about its global 
potential. In fact, the global divide persists on this platform as this continues to remain a dominantly Western preoccupation in spite of the exponential rise of emerging market designers, brands and consumers. Hence, for further research, it is essential to actively investigate why emerging markets are not capitalizing and inhabiting this fashion blogosphere and if there are alternative new media platforms that serve to create a similar culture for this under-examined demographic.

On a special note, Marc Jacobs is worth mentioning given that he defies the common pattern of exclusion of designers of haute couture within this fashion blogosphere and in fact serves as a common factor across these bloggers given that he is followed on Twitter by all these ranked bloggers. Marc Jacobs one can argue is the 'Kevin Bacon' of the fashion world where degrees of separation can be gauged through the linkage with this designer. For future research, it is worth delving into how Marc Jacobs as a professional has managed to position himself within the world of fashion amateurs and why is he so successful in balancing between these two worlds. This study shows that initial findings support the usage of personalization and the casual and accessible approach even when it comes to the world of high culture as Marc Jacobs demonstrates through his Twitter usage. Consequently Marc Jacobs has built up a community of 98,567 followers consisting of fashion professionals as well as random enthusiastic fashion fans and bloggers. Basically, while much literature out there promotes and applies pressure to businesses including those in the fashion industry to embrace these social media platforms as we have seen in this study, there is little empirical success in brands penetrating the top ranking fashion blogs.

Lastly, as we see in this study, trust and authenticity is essential to the success of a blog as several studies have demonstrated such as Bernoff (2009) where it was found that $77 \%$ of people trust information that comes from a person who they know. However, few studies have illustrated how top ranking fashion blogs create a culture of trustworthiness on 
their platform through a complex combination of visual, textual and layout strategies as well as discourse, interactivity, content and networking approaches to their subject. Hence, this paper serves to highlight what constitutes as a successful fashion blog from its authorship and its culture of space as well as this paper emphasizes the tremendous challenges and paradox facing the fashion industry in commercializing and corporatizing of these spaces.

\section{References}

Arora, P. (2012). Typology of Web 2.0 spheres: Understanding the cultural dimensions of social media spaces. Current Sociology, 60 (5), 599-618.

Berendt, B., Navigli, R. (2006). Finding your way through blogspace: Using semantics for cross-domain analysis. AAAI symposium on computational approaches to analyzing weblogs. 2006.

Bernoff, J. (2009). Blogs, Marketing and Trust. Marketing News, issue 0215.09, 17 - 18. Available at: http://mpdev.marketingpower.com/ResourceLibrary/Publications/MarketingNews/2009/ 43/2/Feb_15_ViewPoint_Bernoff.pdf (Retrieved March 21 2013)

Blakley, J. (2010). Lessons from fashion's free culture. Ted Talk. Available at: http://www.ted.com/talks/lang/en/johanna_blakley_lessons_from_fashion_s_free_cultur e.html (Retrieved March 21 2013)

Bollier, L and Racine, D. (2005). Ready to Share: Creativity in Fashion and Digital Culture. Paper presented at conference Ready to Share at Norman Lear Center, January $29^{\text {th }}$ 2005. Available at: http://www.learcenter.org/pdf/RTStranscript.pdf (Retrieved March $212013)$

Bourne, L. (July 9th 2010). Social Media Is Fashion's Newest Muse. Magazine Forbes. Available at: http://www.forbes.com/2010/09/07/fashion-social-networking-customerfeedback-forbes-woman-style-designers.html (Retrieved March 21 2013)

Boram, P., Sookyoung A., \& HaeJung, K. (2010). Blogging: Mediated inpacts of flow on motivational behavior. Journal of research and interactive marketing, 4(1), 6-29

Caslon (2009). Caslon Analytics Blogging. Available at: http://www.caslon.com.au/weblogprofile1.htm (Retrieved March 21 2013)

Easey, M. (2002). Fashion marketing, (Third Ed.),Oxford: Blackwell Science.

Elo, S. and Kynga, S.H. (2008). The qualitative content analysis process. Journal of Advanced Nursing 62(1), 107-115

English, B. (2009). Fashion -Little book of big ideas. London: A\&C Black.

Discher, F., W. (2007). Car blogs and Gift Economy. Information Culture Fall 2007 
Farrell, H. \& Drezner, D. (2008). The power and politics of blogs. Public Choice, (134), 1530

Fionda A. M. and Moore Ch. M. (2008). The anatomy of the luxury fashion brand. Palgrave Macmillan 1350-23IX Brand Management Vol. 16, 5/6, 347-363

Fisher, A. (21 ${ }^{\text {st }}$ February, 2010). The 10 best fashion bloggers. The Observer. http://www.guardian.co.uk/culture/2010/feb/21/10-best-fashion-bloggers\#history-linkbox (Retrieved March 21 2013)

Guzelis, G. (2010). Characterising Succesful Fashion Blogs and Their Evaluation Metrics. Saarbrucken: LAP LAMBERT Academic Publishing.

Hitt A.M., Ireland R.D., Hoskisson R.E., (2009) Strategic management: competitiveness and globalization: concepts \& cases, eighth edition, Cengage Learning Inc., Canada

Hauge, A. (2006, January). Tune of text: Gatekeepers and knowledge diffusion in the fashion industry. Paper presented at DRUID-DIME Academy Winter 2006 PhD Conference, January 26. - 28, 2006. http://www.druid.dk/uploads/tx_picturedb/dw2006-1711.pdf (Retrieved March 21 2013)

Hines, T. and Bruce, M. (2007). Fashion Marketing, Contemporary Issues (Second Ed.), Oxford: Elsevier Ltd.

Juch, C. And Stobbe A. (2005). Blogs: The magic formula of corporate communication? Digital Economy, No. 53, 2 - 10

Kaplan, A.M. and Haenlein, M. (2009). Users of the world, unite! The challenges and opportunities of social media. Business Horizons (2010) 53, 59-68

Kuhn, M. (2007). Interactivity and Prioritizing the Human: A Code of Blogging Ethics. Journal of Mass Media Ethics, 22(1), 18-36

Leitch, L. (November $14^{\text {th }}$ 2009). Burberry's art of the trench checks out power of fashion blogs. The Times. Available at:

http://timesonline.co.uk/tol/life_and_style/women/fashion/article6916560.ece (Retrieved March 21 2013)

Lichtenstein, S. (2009).The Decline of Experts in the Age of Web 2.0: Lay Blogger Perceptions of Experts. ACIS 2009 Proceedings. Paper 5, 1034 - 1044

Liu, Ch. M. and Donath, J.S. (2006). Urbanhermes: Social Signaling with Electronic Fashion. Retrieved from: http://smg.media.mit.edu/papers/cml/chi2006.pdf (Retrieved March 21 2013)

Lee, T. S., Leung, C.S., Zhang, Z. M. (2009). Fashion Brand Image Marketing: Brand Image and Brand Personality. RJTA Vol. 4 No. 2, 60-67

Leung, L. (2009). User-generated content on the Internet: An examination of gratifications, civic engagement and psychological empowerment. New Media \& Society, 11(8), 13271347

McDonald, C. and Ounis, I. (2008). Key Blog Distillation: Ranking Aggregates. Paper presented at conference CIKM'08, October 26 - 30, 2008, Napa Valley, California, 
USA. http://terrierteam.dcs.gla.ac.uk/publications/macdonald08cikm.pdf (Retrieved March 21 2013)

Menkes, S. (February $17^{\text {th }}$ 2012). An American Crisis of Identity. International Herald Tribune. Available at: http://www.nytimes.com/2012/02/18/fashion/18ihtrny18.html?_r=1\&ref=newyorkfashi onweek (Retrieved March 21 2013)

Nardi, B.A., Schiano, D.J., Gumbrecht, M. and Swartz, L. (2004). Why we blog. Communications of the ACM, Vol. 47 No. 12

Okonkwo, U. (2007). Luxury Fashion Branding - Trends, Tactics, Techniques. London: Palgrave MacMillan.

Pan, B., MacLaurin, T., Crotts, J.,C. (2006). Travel Blogs and the implication for destination marketing. Journal of Travel research 2007. Available at:

http://www.panb.people.cofc.edu/pan/JTR-TravelBlogs-Pan_etal.pdf (Retrieved March $212013)$

Picard, R., G. (2000). Changing Business Models of Online Content Services - Their Implications for Multimedia and Other Content Producers. JMM - Internatioanal Journal of Media Management, Vol. 2 - No. II - 2000

Royal Pingdom (January $12^{\text {th }} 2011$ ). Internet 2010 in numbers. Retrieved January $29^{\text {th }} 2012$ from: http://royal.pingdom.com/2011/01/12/internet-2010-in-numbers/

Shao, G. (2008). Understanding the appeal of user-generated media: a uses and gratification perspective. Internet Research, 19(1), 7-25.

Sum, M., Zhu, F (2011). Ad Revenue and Content Commercialization: Evidence from Blogs. The Networks, Electronic Commerce, and Telecommunications. Available at: http://archive.nyu.edu/bitstream/2451/31448/2/Sun_Zhu_11_32.pdf

Yang, S.U. and Lim, J.S. (2009). The Effects of Blog-Mediated Public Relations (BMPR) on Relational Trust. Journal of Public Relations Research, 21(3), 2009, 341 - 359

Zhao, K., Kumar, A. (2012). Who blogs what: understanding of publishing behavior of content. World, Wide, Web, May 2012.

Zhao, D. and Rosson, M. B. (2009). How and Why People Twitter: The Role that Micro Blogging Plays in Informal Communication at Work. The paper presented at the conference GROUP'04, May 10-13, 2009, Sanibel Island, Florida, USA. Available at: http://www.pensivepuffin.com/dwmcphd/syllabi/info447_au10/readings/zhao.rosson.T witter.GROUP09.pdf (Retrieved March 21 2013)

Appendix A: List of top 10 ranked bloggers from the Alice Fisher Index 2010: The Guardian

1. Tavi Gevinson - tavi-thenewgirlintown.blogspot.com

2. Gary Card - garycardiology.blogspot.com

3. Scott Schuman - thesartorialist.blogspot.com

4. Susanna Lau - stylebubble.typepad.com

5. David Fischer - highsnobiety.com

6. Joe Sinclair and Katie Mackay - whatkatiewore.com

7. Jessica Morgan and Heather Cocks - gofugyourself.celebuzz.com

8. Gabi Gregg - youngfatandfabulous.com 
9. Mikael Colville-Andersen - copenhagencyclechic.com

10. Will Boehlke - asuitablewardrobe.dynend.com 